\title{
Parental overweight and hypertension are associated with their children's blood pressure
}

\author{
Renying $\mathrm{Xu}^{1}$, Xiaomin Zhang ${ }^{1}$, Yiquan Zhou ${ }^{1}$, Yanping $\mathrm{Wan}^{{ }^{*}}$ and Xiang Gao ${ }^{2^{*}}$ (D)
}

\begin{abstract}
Background: We evaluated the association between parental factors (overweight, history of hypertension, and education level) and children's blood pressure status. Further, we evaluated to what extent the potential association could be interpreted by children's adiposity indices.

Methods: The current study included 3316 Chinese school students (1579 girls and 1737 boys, aged 6-14 years) and their parents. Parents reported information on their height, body weight, history of hypertension, and the highest education level. Trained medical staff measured children's blood pressure, height, body weight, waist circumference (WC), and percentage of body fat (PBF, assessed by bio-impedance method). Z-score of all three indices were calculated and used in the analysis. We used generalized linear model to evaluate the association between parental information and z-score of children's blood pressure. Meditation analysis was used to evaluate the proportion contributed by z-score of children's adiposity indices (BMI, WC, and PBF).
\end{abstract}

Results: We found that parental overweight and hypertension, but not parental education level, were significantly associated with children's systolic and diastolic blood pressure ( $P<0.05$ for all). Approximately $30.4-92.2 \%$ of the association between these two parental factors and children's systolic blood pressure were mediated by children's adiposity indices, and $22.3-55.6 \%$ for children's diastolic blood pressure. The strongest meditative factor, among the three obesity indices, was children's BMI z-score.

Conclusions: The association between parental factors and children's blood pressure was mainly mediated by children's adiposity indices.

Keywords: Parents, Children, Body mass index (BMI), Waist circumference (WC), Percentage of body fat (PBF), Blood pressure

\section{Background}

The prevalence of hypertension among Chinese children and adolescents increased from 6.9 to $10.7 \%$ in the past two decades based on a National survey [1]. Without proper intervention, childhood hypertension will track into adult and dramatically exaggerate adult hypertension [2] and related cardiovascular diseases such as

\footnotetext{
* Correspondence: wanyp204@63.com; xxg14@psu.edu

The study was supported by the grants from Pu Dong Medical Bureau (PW2016D-05), and by the grant from Shanghai Key Laboratory of Pediatric Gastroenterology and Nutrition (No.17DZ2272000)

'Department of Clinical Nutrition, Ren Ji Hospital, School of Medicine, Shanghai Jiao Tong University, Shanghai, China

${ }^{2}$ Department of Nutritional Science, The Pennsylvania State University, University Park, PA 16802, USA
}

stroke and acute myocardial infarction [3, 4]. Identifying risk factors for childhood hypertension is of significance to ameliorate medical burden, which is associated with adulthood cardiovascular diseases.

Several parental factors, such as obesity [5-7], history of hypertension [8-10], education level [11-13], and family income $[11,12,14,15]$, were shown to be associated with childhood hypertension. It is meaningful to block the transmission from parents to children if we could find the underlying mediators. Previous studies reported that these associations might be mediated by children's body mass index (BMI), a key driving factor for childhood hypertension [12, 14-16]. However, evidence remains inconsistent: positive $[5,6]$ and null [7] 
association between parental BMI and children's blood pressure were reported in previous studies. Further, whether waist circumference (WC) and percentage of body fat $(\mathrm{PBF})$ in parents, which are believed to be better indices in reflecting body fat than BMI, are associated with offspring blood pressure status remains unclear. Therefore, we performed a cross-sectional study in 3316 Chinese parents-children trios to evaluate the association between parental factors (overweight, history of hypertension, and education level) and childhood blood pressure status. We further evaluated meditative effect of children's adiposity indices, including BMI, waist circumference (WC), and percentage of body fat $(\mathrm{PBF})]$ on these potential associations.

\section{Methods}

\section{Study population}

The current study was conducted in five primary schools in Gao Hang Town, Shanghai, China, as detailed previously [17]. Parental information including height, body weight, history of hypertension, and the highest education level was self-reported via a questionnaire. Trained medical staff measured children's blood pressure in September 2014. We have 28 investigators to perform the survey. Among them, 6 doctors and 4 nurses assessed children's blood pressure, 10 registered dietitians conducted face-to-face interview, and the remain trained medical staffs collected anthropometrical data (e.g., body weight and waist circumference). Approximately 300 children were surveyed during each visit. The number of eligible participants was 3781, after excluding those who declined to participate the study $(n=58)$, those born preterm $(n=77)$, those with missing data $(n=325)$, this resulted in 3321 participants. We further excluded five participants old than 14years, included were 3316 parents-children trios (1579 girls and 1737 boys, aged 6-14 years) in the analysis. The details of participant recruitment were shown in Additional file 1: Figure S1. Parents signed informed consent forms. The study was approved by the Ethics Committee of Ren Ji Hospital, School of Medicine, Shanghai Jiao Tong University.

\section{Exposures}

Parents reported their information on height, body weight, history of hypertension, and the highest education level via a questionnaire. Parental BMI was calculated and categorized as following: 'normal' $(\mathrm{BMI}<24.0$ $\mathrm{kg} / \mathrm{m}^{2}$ ), or 'overweight' (BMI $\geq 24.0 \mathrm{~kg} / \mathrm{m}^{2}$ ) according to the Working Group of Obesity in China (WGOC) criteria for adults [18]. Parental education level was categorized as 'low' ( $\leq$ middle school) or 'high' ( $\geq$ high school) while history of hypertension was categorized as 'yes' or 'no'.

\section{Outcome}

Children's resting blood pressure (BP) was measured by 6 doctors and 4 nurses twice on the children's right arm in a quiet room after resting for at least $10 \mathrm{~min}$, using a mercury sphygmomanometer and a special cuff that fit $2 / 3$ of the children's arm. Systolic blood pressure (SBP) is the point at which the onset of Korotkoff sounds and the fourth Korotkoff sound (K4) was used to define diastolic blood pressure (DBP) [19]. The interval between the two blood pressure measurements was at least 10 min and the average value of BP was recorded to the nearest $1 \mathrm{mmHg}$. Because children's body size changes rapidly during development and blood pressure keeps changing as well, $\mathrm{z}$-score of blood pressure was calculated based on a national survey [20].

\section{Potential mediators}

We examined whether children's obesity indices (BMI, $\mathrm{WC}$, and $\mathrm{PBF}$ ) were mediators for the association between parental information (e.g., obesity status) and childhood blood pressure. Children's height (to the nearest $0.1 \mathrm{~cm}$ ), weight (to the nearest $0.1 \mathrm{~kg}$ ), and body fat (BIA method; TBF-410, Tokyo, Japan) were measured while children were barefoot and in underwear. Body fat was recorded as PBF (fat mass/body weight*100) to the nearest $0.1 \%$. BMI was calculated as the body weight $(\mathrm{kg})$ divided by the height squared $\left(\mathrm{m}^{2}\right)$. BMI z-score was calculated according to the Shanghai age and sex specific height and body weight 2007 standards [21]. WC was measured at the midpoint between the iliac crest and the lower rib (to the nearest $0.1 \mathrm{~cm}$ ). Z-score of PBF and WC was also calculated [22, 23].

\section{Assessment of other potential confounders}

We collected children's information on age, sex, birth weight, infant feeding pattern (breastfeeding, part breastfeeding, or bottle-feeding), physical activities $(<1$ or $\geq 1 \mathrm{~h}$ per day), and night sleep duration ( $<9$ or $\geq 9 \mathrm{~h}$ per day), consumption of carbonated beverage ( $\leq 3$ or $\geq 4$ bottles per week), western fast food ( $\leq 4$ or $\geq 5$ times per month), traditional Chinese fried food ( $\leq 4$ or $\geq 5$ times per week), and processed meat ( $\leq 4$ or $\geq 5$ times per week), by the aforementioned questionnaire, which was completed by the parents.

\section{Statistical analyses}

We performed all statistical analyses by SAS version 9.4 (SAS Institute, Inc., Cary, NC). Formal hypothesis testing was two-sided with a significant level of 0.05 .

Potential mediator were examined using the method described by Baron and Kenny's [24]. We used PROC CORR to evaluate the association between parental BMI and z-score of children's adiposity indices and z-score of blood pressure adjusting for children's age, sex, birth 
weight, infant feeding, diet, physical activities, and night sleep. PROC GLM was used to evaluate the association between parental BMI and other factors (history of hypertension and education level) and children's blood pressure. We included a number of potential confounders in the model: age $(y)$, sex, height $(\mathrm{cm})$, birth weight (g), infant feeding (breastfeeding, part breastfeeding or bottle-feeding), consumption of carbonated beverage ( $\leq 3$ or $\geq 4$ bottles per week), western fast food ( $\leq 4$ or $\geq 5$ times per month), traditional Chinese fried food ( $\leq 4$ or $\geq 5$ times per week), and processed meat $(\leq 4$ or $\geq$ 5 times per week), daily physical activities $(<1 \mathrm{~h}$ or $\geq 1$ $\mathrm{h}$ ), and night sleep ( $<9$ or $\geq 9 \mathrm{~h}$ per day).

To evaluate total effect, indirect effect, and direct effect of the association between parental information and z-score of children's blood pressure, we performed two GLM regression model: regressing the mediator(s) on the exposures and confounders (as mentioned above), and regressing the outcome on the exposure, mediator(s), and confounders, from which we obtained the indirect effect, direct effect, and the total effect [25]. The meditative proportion was calculated as indirect effect divided by total effect.

\section{Results}

The average paternal and maternal BMI was $24.3 \pm 3.0$ $\mathrm{kg} / \mathrm{m}^{2}$ and $21.8 \pm 2.9 \mathrm{~kg} / \mathrm{m}^{2}$ respectively; while average SBP and DBP for children was $101.1 \pm 11.3 \mathrm{mmHg}$ and $61.8 \pm 8.2 \mathrm{mmHg}$. The differences in children's z-score of BMI, WC and PBF were significant between normal-weight and overweight parents (Table 1). Both parental BMI and z-score of all three children's adiposity indices were associated with $\mathrm{z}$-score of blood pressure in boys and girls (Additional file 1: Table S1).

Children with overweight, or hypertensive parents had higher z-score of blood pressure, compared to those whose parents' BMI was normal, or without hypertension, respectively. (Tables 2 and 3, model 2). The results were similar when we assessed the association between parental overweight, hypertension, education, and the value of blood pressure (Additional file 1: Table S2). After further adjustment for children's BMI z-score, the associations lost significance except for a marginal association between paternal history of hypertension and children's SBP z-score (Tables 2 and 3, model 3). Adjusting z-score of children's WC and PBF dramatically attenuated the association, but it remained significant except the relationship between maternal overweight, history of hypertension and their children's SBP z-score (Tables 2 and 3, model 4-5). We did not find association between parental education and childhood blood pressure (Tables 2 and 3 , model 2).

The meditative proportion for the association between paternal overweight and children's SBP was 68.1, 51.8, and $46.3 \%$ for z-score of children's BMI, WC, and PBF, respectively, and it ranged from 30.7 to $52.4 \%$ for the association between paternal overweight and children's DBP z-score (Table 4). The proportion ranged from 50.7 to $92.2 \%$ for maternal overweight and SBP z-score while it was between 29.6 to $55.6 \%$ for maternal overweight and DBP z-score (Table 5). It is similar for the association between parental history of hypertension and z-score of children's blood pressure (Tables 4 and 5). BMI z-score was the strongest mediator among the three adiposity indices. Further classified children into four groups based on parental body weight generated similar results with main analysis (Additional file 1: Table S3). When classified children into four groups based on history of hypertension, the coefficient lost significance $(r$ $=0.12,95 \%$ confidence interval: $-0.22,0.46)$ when comparing two extreme groups (Additional file 1: Table S4).

\section{Discussions}

In this study including 3361 Chinese parents-children trios, we found that parental overweight and hypertension status were associated with children's blood pressure. However, the association was largely mediated by children's obesity status. The strengths of the current study included a large sample size, a comprehensible analysis of three adiposity indices, and adjustment for a wide range of potential confounders such as birthweight, diet, physical activities, and sleep duration.

Our study found that parental overweight and history of hypertension were associated with childhood blood pressure. Consisted with our study, a large cross-sectional study (14,400 children, 7-18 years old) reported parental BMI had a weak but significant association with children's blood pressure [6]. Parental overweight and obesity were also associated with a high likelihood of elevated blood pressure $(\geq$ age- and sexspecific 90th percentile) in their children [6]. In a cohort study included 3864 children with 5 years of follow-up, paternal pre-conceptional BMI was associated with children's blood pressure at age 5 even after adjusting children's height and body weight [5]. Contrast to our results, Veena et al. [7] did not find any significant association between parental overweight and children's SBP in a cohort study including 504 Indian children and their parents after 9.5-year follow-up. However, anthropometric measurements were recorded for mothers at the baseline ( $\approx 30$ weeks of gestation) and fathers at 5 years after the baseline. The association between parental history of hypertension and children's blood pressure was also confirmed by previous studies [8-10]. The possible mechanism remains unclear and both genetic and environmental factors could involve [26]. Children's diet and behavior are generally modelled by their parents, especially in pre-adolescent stage. Parental diet and behavior 
Table 1 Demographic characteristics in 3316 Chinese school students across parental groups

\begin{tabular}{|c|c|c|c|c|c|c|c|}
\hline \multirow[t]{2}{*}{ Variable } & \multirow[t]{2}{*}{ Group } & \multicolumn{2}{|l|}{ Father } & \multirow{2}{*}{$\begin{array}{l}P \\
\text { value }\end{array}$} & \multicolumn{2}{|l|}{ Mother } & \multirow{2}{*}{$\begin{array}{l}P \\
\text { value }\end{array}$} \\
\hline & & Normal & overweight & & Normal & Overweight & \\
\hline Sample number & - & 2219 & 1097 & - & 2892 & 424 & - \\
\hline Age, y & - & $9.5 \pm 2.1$ & $8.8 \pm 1.9$ & $<0.01$ & $9.2 \pm 2.1$ & $9.1 \pm 2.0$ & 0.1 \\
\hline Sex, girls, $\%$ & - & 48.0 & 47.0 & 0.59 & 47.4 & 49.3 & 0.46 \\
\hline Birth weight, $g$ & - & $3379 \pm 453$ & $3391 \pm 458$ & 0.49 & $3371 \pm 447$ & $3465 \pm 496$ & $<0.01$ \\
\hline Height, cm & - & $141.1 \pm 13.7$ & $138.4 \pm 12.6$ & $<0.01$ & $140.0 \pm 13.3$ & $139.9 \pm 13.4$ & 0.84 \\
\hline Body weight, $\mathrm{kg}$ & - & $36.0 \pm 12.8$ & $35.7 \pm 12.5$ & 0.53 & $35.5 \pm 12.5$ & $37.7 \pm 13.2$ & $<0.01$ \\
\hline BMI z-score ${ }^{a}$ & - & $-0.09(-0.89,0.74)$ & $0.29(-0.48,1.11)$ & $<0.01$ & $-0.01(-0.81,0.84)$ & $0.47(-0.29,1.28)$ & $<0.01$ \\
\hline WC $z$-score ${ }^{a}$ & - & $0.18(-0.46,0.92)$ & $0.45(-0.21,1.2)$ & $<0.01$ & $0.24(-0.4,1.0)$ & $0.61(-0.04,1.38)$ & $<0.01$ \\
\hline PBF $z$-score ${ }^{a}$ & - & $-0.5(-1.01,0.29)$ & $-0.26(-0.86,0.56)$ & $<0.01$ & $-0.46(-0.98,0.33)$ & $-0.05(-0.77,0.81)$ & $<0.01$ \\
\hline SBP z-score ${ }^{a}$ & - & $2.32(0.003,4.58)$ & $2.76(0.24,4.61)$ & 0.17 & $2.45(0.13,4.57)$ & $2.37(0.21,4.8)$ & 0.53 \\
\hline DBP $z$-score ${ }^{a}$ & - & $-2.38(-4.48,-0.26)$ & $-2.63(-4.39,-0.14)$ & 0.16 & $-2.61(-4.46,-0.25)$ & $-1.9(-4.31,-0.05)$ & 0.02 \\
\hline \multirow[t]{3}{*}{ Infant feeding, \% } & Breast & 50.2 & 50.7 & 0.89 & 50.4 & 50.5 & 0.94 \\
\hline & Part breast & 19.0 & 17.2 & & 18.4 & 18.6 & \\
\hline & Bottle & 30.7 & 32.0 & & 31.2 & 30.9 & \\
\hline \multirow[t]{2}{*}{ Western fast food, $\%$} & $\leq 4 /$ month & 97.8 & 97.7 & 0.9 & 97.8 & 97.4 & 0.59 \\
\hline & $\geq 5$ /month & 2.2 & 2.3 & & 2.2 & 2.6 & \\
\hline \multirow[t]{2}{*}{ Traditional Chinese fried food, \% } & $\leq 4 /$ week & 98.3 & 99.3 & 0.03 & 98.6 & 98.8 & 0.73 \\
\hline & $\geq 5 /$ week & 1.7 & 0.7 & & 1.4 & 1.2 & \\
\hline \multirow[t]{2}{*}{ Processed meat, \%, } & $\leq 4 /$ week & 97.7 & 99.0 & $<0.01$ & 98.1 & 98.1 & 0.98 \\
\hline & $\geq 5$ /week & 2.3 & 1.0 & & 1.9 & 1.9 & \\
\hline \multirow[t]{2}{*}{ Carbonated beverage, $\%$} & $\leq 3 /$ week & 90.9 & 92.2 & 0.21 & 91.4 & 90.6 & 0.57 \\
\hline & $\geq 4$ /week & 9.1 & 7.8 & & 8.6 & 9.4 & \\
\hline \multirow[t]{2}{*}{ Daily physical activity, \% } & $<1 \mathrm{~h}$ & 47.1 & 32.3 & $<0.01$ & 43.5 & 33.3 & $<0.01$ \\
\hline & $\geq 1 \mathrm{~h}$ & 52.9 & 67.6 & & 56.5 & 66.7 & \\
\hline \multirow[t]{2}{*}{ Night sleep duration, \% } & $<9 \mathrm{~h}$ & 24.8 & 20.8 & 0.01 & 23.5 & 23.1 & 0.86 \\
\hline & $\geq 9 \mathrm{~h}$ & 75.2 & 79.2 & & 76.5 & 76.9 & \\
\hline \multirow[t]{2}{*}{ Paternal education level, \% } & $\leq$ middle school & 53.5 & 54.7 & 0.51 & 52.7 & 61.8 & $<0.01$ \\
\hline & zhigh school & 46.5 & 45.3 & & 47.3 & 38.2 & \\
\hline \multirow[t]{2}{*}{ Parental history of hypertension, $\%$} & No & 89.1 & 72.6 & $<0.01$ & 84.1 & 80.4 & 0.06 \\
\hline & Yes & 10.9 & 27.4 & & 15.9 & 19.6 & \\
\hline \multirow[t]{2}{*}{ Maternal education level, \% } & $\leq$ middle school & 56.0 & 61.1 & $<0.01$ & 56.0 & 68.6 & $<0.01$ \\
\hline & zhigh school & 44.0 & 38.9 & & 44.0 & 31.4 & \\
\hline \multirow[t]{2}{*}{ Maternal history of hypertension, $\%$} & No & 96.6 & 95.8 & 0.27 & 97.8 & 85.9 & $<0.01$ \\
\hline & Yes & 3.4 & 4.2 & & 2.1 & 14.1 & \\
\hline
\end{tabular}

$B M I$ body mass index, $W C$ waist circumference, $P B F$ percentage of body fat, $S B P$ systolic blood pressure, $D B P$ diastolic blood pressure Parental BMI was categorized into normal $\left(B M I<24.0 \mathrm{~kg} / \mathrm{m}^{2}\right)$ and overweight $\left(\mathrm{BMI} \geq 24.0 \mathrm{~kg} / \mathrm{m}^{2}\right)$ according to the Working Group of Obesity in China (WGOC) criteria for adults

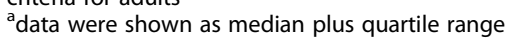

were reported to be associated with their offspring's correspondent indices [27, 28]. Epigenetic information (e.g., overweight and hypertension) could print on parental chromosome, which could be inherited by their offspring, thus exerts potential effects on their offspring's development [29]. Inconsistent with previous study which reported children with two hypertensive parents were in the highest risk of developing childhood hypertension [30], we failed to find significant differences between children with two normal parents and those with two hypertensive parents. One possible interpretation is the small sample size in the latter group $(n=50)$.

Although the differences in ethnicity, statistical method, and when parental information were collected, could explain part of the disparities among the studies, failure to consider children's adiposity indices could be one of major limitations of previous studies [6, 8-10, 13-15]. Few studies were performed to analyze meditative effects of the association between parental information and children's blood pressure [11, 12]. A cohort 
Table 2 Mean difference and standard deviation of z-score of SBP and DBP across paternal groups in 3316 Chinese school students

\begin{tabular}{|c|c|c|c|c|c|c|c|c|c|c|}
\hline \multirow[b]{2}{*}{ Variable } & \multirow[b]{2}{*}{ Model } & \multicolumn{3}{|c|}{ Body weight } & \multicolumn{3}{|c|}{ History of hypertension } & \multicolumn{3}{|c|}{ Education level } \\
\hline & & Normal & Overweight & $P$ value & No & Yes & $P$ value & Low & High & $P$ value \\
\hline & Number & 2219 & 1097 & - & 2773 & 543 & - & 1787 & 1529 & - \\
\hline \multirow[t]{5}{*}{ SBP z-score } & Model 1 & 0 (ref) & $0.29 \pm 0.1$ & 0.004 & 0 (ref) & $0.24 \pm 0.06$ & $<0.001$ & 0 (ref) & $-0.04 \pm 0.05$ & 0.35 \\
\hline & Model 2 & 0 (ref) & $0.18 \pm 0.05$ & $<0.001$ & 0 (ref) & $0.23 \pm 0.06$ & $<0.001$ & 0 (ref) & $-0.04 \pm 0.05$ & 0.37 \\
\hline & Model 3 & 0 (ref) & $0.06 \pm 0.05$ & 0.23 & 0 (ref) & $0.16 \pm 0.05$ & 0.008 & 0 (ref) & $-0.05 \pm 0.05$ & 0.29 \\
\hline & Model 4 & 0 (ref) & $0.09 \pm 0.0 .05$ & 0.07 & 0 (ref) & $0.16 \pm 0.05$ & 0.006 & 0 (ref) & $-0.05 \pm 0.05$ & 0.25 \\
\hline & Model 5 & 0 (ref) & $0.1 \pm 0.0 .05$ & 0.03 & 0 (ref) & $0.15 \pm 0.06$ & 0.01 & 0 (ref) & $-0.03 \pm 0.05$ & 0.47 \\
\hline \multirow[t]{5}{*}{ DBP z-score } & Model 1 & 0 (ref) & $0.17 \pm 0.04$ & $<0.001$ & 0 (ref) & $0.2 \pm 0.05$ & $<0.001$ & 0 (ref) & $-0.03 \pm 0.04$ & 0.38 \\
\hline & Model 2 & 0 (ref) & $0.16 \pm 0.04$ & $<0.001$ & 0 (ref) & $0.18 \pm 0.05$ & $<0.001$ & 0 (ref) & $-0.04 \pm 0.04$ & 0.28 \\
\hline & Model 3 & 0 (ref) & $0.08 \pm 0.05$ & 0.11 & 0 (ref) & $0.09 \pm 0.06$ & 0.11 & 0 (ref) & $-0.05 \pm 0.04$ & 0.22 \\
\hline & Model 4 & 0 (ref) & $0.11 \pm 0.04$ & 0.006 & 0 (ref) & $0.14 \pm 0.05$ & 0.005 & 0 (ref) & $-0.05 \pm 0.04$ & 0.21 \\
\hline & Model 5 & 0 (ref) & $0.11 \pm 0.04$ & 0.005 & 0 (ref) & $0.13 \pm 0.05$ & 0.01 & 0 (ref) & $-0.04 \pm 0.04$ & 0.33 \\
\hline
\end{tabular}

Paternal overweight includes overweight and obese $\left(\mathrm{BMI} \geq 24.0 \mathrm{~kg} / \mathrm{m}^{2}\right)$. Low education level refers as the highest level $\leq$ middle school and high as $\geq$ high school. SBP systolic blood pressure, DBP diastolic blood pressure

Model 1: adjusted for age (y) and sex

Model 2: adjusted for variables in model 1 and further adjusted for height $(\mathrm{cm})$, birth weight $(\mathrm{g})$, infant feeding (breastfeeding, part breastfeeding or bottlefeeding), physical activities $(<1 \mathrm{~h}$ or $\geq 1 \mathrm{~h}$ per day), night sleep duration $(<9 \mathrm{~h}$ or $\geq 9 \mathrm{~h}$ per day), consumption of carbonated beverage ( $\leq 3$ or $\geq 4$ bottles per week), western fast food ( $\leq 4$ or $\geq 5$ times per month), traditional Chinese fried food ( $\leq 4$ or $\geq 5$ times per week), and processed meat ( $\leq 4$ or $\geq 5$ times per week)

Model 3: adjusted for variables in model 2 and further adjusted $z$-score of children's BMI

Model 4: adjusted for variables in model 2 and further adjusted z-score of children's waist circumference

Model 5: adjusted for variables in model 2 and further adjusted $z$-score of children's percentage of body fat

study analyzed 5604 Hongkong adolescents ( $\approx 13$ years old) and found that adolescent BMI (24\%) mediated the association between parental education and adolescent blood pressure, followed by maternal BMI (18\%) [12]. Another cohort study performed in 5843 Netherland children and they also found the association between maternal education and children's blood pressure was mediated by both children's and maternal pre-conceptional BMI [11]. One cross-sectional study was performed in 2727 Chinese adolescents (12-16 years) to evaluate the association between parental overweight and the risk of childhood metabolic syndrome.

Table 3 Mean difference and standard deviation of z-score of SBP and DBP across maternal groups in 3316 Chinese school students

\begin{tabular}{|c|c|c|c|c|c|c|c|c|c|c|}
\hline \multirow[b]{2}{*}{ Variable } & \multirow[b]{2}{*}{ Model } & \multicolumn{3}{|c|}{ Body weight } & \multicolumn{3}{|c|}{ History of hypertension } & \multicolumn{3}{|c|}{ Education level } \\
\hline & & Normal & Overweight & $P$ value & Negative & Positive & $P$ value & Low & High & $P$ value \\
\hline & Number & 2892 & 424 & - & 3194 & 122 & - & 1902 & 1404 & - \\
\hline \multirow[t]{5}{*}{ SBP z-score } & Model 1 & 0 (ref) & $0.2 \pm 0.07$ & 0.003 & 0 (ref) & $0.31 \pm 0.12$ & 0.009 & 0 (ref) & $-0.005 \pm 0.05$ & 0.91 \\
\hline & Model 2 & 0 (ref) & $0.2 \pm 0.06$ & $<0.001$ & 0 (ref) & $0.3 \pm 0.12$ & 0.01 & 0 (ref) & $-0.006 \pm 0.05$ & 0.91 \\
\hline & Model 3 & 0 (ref) & $0.01 \pm 0.07$ & 0.84 & 0 (ref) & $0.14 \pm 0.13$ & 0.27 & 0 (ref) & $-0.005 \pm 0.05$ & 0.86 \\
\hline & Model 4 & 0 (ref) & $0.1 \pm 0.06$ & 0.11 & 0 (ref) & $0.15 \pm 0.12$ & 0.19 & 0 (ref) & $-0.01 \pm 0.05$ & 0.79 \\
\hline & Model 5 & 0 (ref) & $0.09 \pm 0.06$ & 0.13 & 0 (ref) & $0.13 \pm 0.12$ & 0.27 & 0 (ref) & $-0.001 \pm 0.05$ & 0.98 \\
\hline \multirow[t]{5}{*}{ DBP z-score } & Model 1 & 0 (ref) & $0.21 \pm 0.05$ & $<0.001$ & 0 (ref) & $0.31 \pm 0.1$ & 0.002 & 0 (ref) & $0.02 \pm 0.04$ & 0.69 \\
\hline & Model 2 & 0 (ref) & $0.19 \pm 0.05$ & $<0.001$ & 0 (ref) & $0.31 \pm 0.1$ & 0.002 & 0 (ref) & $-0.004 \pm 0.04$ & 0.91 \\
\hline & Model 3 & 0 (ref) & $0.09 \pm 0.06$ & 0.15 & 0 (ref) & $0.19 \pm 0.11$ & 0.08 & 0 (ref) & $-0.006 \pm 0.04$ & 0.88 \\
\hline & Model 4 & 0 (ref) & $0.14 \pm 0.05$ & 0.009 & 0 (ref) & $0.22 \pm 0.1$ & 0.03 & 0 (ref) & $-0.006 \pm 0.04$ & 0.84 \\
\hline & Model 5 & 0 (ref) & $0.13 \pm 0.05$ & 0.02 & 0 (ref) & $0.2 \pm 0.1$ & 0.047 & 0 (ref) & $-0.001 \pm 0.04$ & 0.97 \\
\hline
\end{tabular}

Paternal overweight includes overweight and obese $\left(\mathrm{BMI} \geq 24.0 \mathrm{~kg} / \mathrm{m}^{2}\right)$. Low education level refers as the highest level $\leq \mathrm{middle}$ school and high as $\geq$ high school. $S B P$ systolic blood pressure, DBP diastolic blood pressure

Model 1: adjusted for age (y) and sex

Model 2: adjusted for variables in model 1 and further adjusted for height $(\mathrm{cm})$, birth weight $(\mathrm{g})$, infant feeding (breastfeeding, part breastfeeding or bottlefeeding), physical activities ( $<1 \mathrm{~h}$ or $\geq 1 \mathrm{~h}$ per day), night sleep duration $(<9 \mathrm{~h}$ or $\geq 9 \mathrm{~h}$ per day), consumption of carbonated beverage ( $\leq 3$ or $\geq 4$ bottles per week), western fast food ( $\leq 4$ or $\geq 5$ times per month), traditional Chinese fried food ( $\leq 4$ or $\geq 5$ times per week), and processed meat ( $\leq 4$ or $\geq 5$ times per week)

Model 3: adjusted for variables in model 2 and further adjusted z-score of children's BMI

Model 4: adjusted for variables in model 2 and further adjusted z-score of children's waist circumference

Model 5: adjusted for variables in model 2 and further adjusted z-score of children's percentage of body fat 
Table 4 Adjusted meditative effect of z-score of children's adiposity indices for the association between paternal overweight and history of hypertension, and z-score of children's blood pressure in 3316 Chinese school students

\begin{tabular}{|c|c|c|c|c|c|}
\hline \multirow[t]{2}{*}{ Mediator } & \multirow[t]{2}{*}{ Effect } & \multicolumn{2}{|l|}{ Overweight } & \multicolumn{2}{|c|}{ History of hypertension } \\
\hline & & SBP z-score & DBP z-score & SBP z-score & DBP z-score \\
\hline & Total effect & $0.18(0.08,0.27)$ & $0.16(0.08,0.24)$ & $0.23(0.12,0.35)$ & $0.18(0.08,0.28)$ \\
\hline \multirow[t]{3}{*}{ BMI z-score } & Indirect & $0.12(0.09,0.15)$ & $0.08(0.06,0.11)$ & $0.08(0.04,0.12)$ & $0.09(0.06,0.12)$ \\
\hline & Direct & $0.06(-0.03,0.15)$ & $0.08(-0.02,0.17)$ & $0.16(0.04,0.27)$ & $0.09(-0.02,0.21)$ \\
\hline & Proportion & $68.1 \%$ & $52.4 \%$ & $33.8 \%$ & $48.0 \%$ \\
\hline \multirow[t]{3}{*}{ WC z-score } & Indirect & $0.09(0.06,0.12)$ & $0.05(0.03,0.07)$ & $0.07(0.04,0.1)$ & $0.04(0.02,0.06)$ \\
\hline & Direct & $0.09(-0.005,0.18)$ & $0.11(0.03,0.19)$ & $0.16(0.05,0.28)$ & $0.14(0.04,0.24)$ \\
\hline & Proportion & $51.1 \%$ & $31.5 \%$ & $30.4 \%$ & $22.3 \%$ \\
\hline \multirow[t]{3}{*}{ PBF z-score } & Indirect & $0.08(0.05,0.1)$ & $0.05(0.03,0.07)$ & $0.08(0.05,0.12)$ & $0.05(0.03,0.08)$ \\
\hline & Direct & $0.1(0.01,0.19)$ & $0.11(0.03,0.19)$ & $0.15(0.04,0.27)$ & $0.13(0.03,0.23)$ \\
\hline & Proportion & $46.3 \%$ & $30.7 \%$ & $35.1 \%$ & $29.4 \%$ \\
\hline
\end{tabular}

Paternal overweight includes overweight and obese $\left(B M I \geq 24.0 \mathrm{~kg} / \mathrm{m}^{2}\right)$. SBP systolic blood pressure, DBP diastolic blood pressure. $B M I$ body mass index, $W C$ waist circumference, PBF percentage of body fat

Adjusted for age $(\mathrm{y})$ and sex, height $(\mathrm{cm})$, birth weight $(\mathrm{g})$, infant feeding (breastfeeding, part breastfeeding or bottle-feeding), physical activities $(<1 \mathrm{~h}$ or $\geq 1 \mathrm{~h}$ per day), night sleep duration ( $<9 \mathrm{~h}$ or $\geq 9 \mathrm{~h}$ per day), consumption of carbonated beverage ( $\leq 3$ or $\geq 4$ bottles per week), western fast food ( $\leq 4$ or $\geq 5$ times per month), traditional Chinese fried food ( $\leq 4$ or $\geq 5$ times per week), and processed meat ( $\leq 4$ or $\geq 5$ times per week)

Proportion of meditative effect $=$ indirect effect/total effect* $100 \%$

The result also showed children's BMI represented $66.9-72.9 \%$ of the effect of parental overweight on potential metabolic syndrome (children with one or two risk components of metabolic syndrome) [16]. As in our study, children's adiposity indices could explain a large part of the association between parental overweight, history of hypertension, and children's blood pressure. Including children's adiposity indices either made the association loss significance or dramatically attenuated the association. The mechanism of mediation remains unclear. As obesity is responsible for most of hypertension [31], thus could explain why adiposity indices (BMI, $\mathrm{WC}$, and $\mathrm{PBF}$ ) mediated the association between parental factors and childhood blood pressure.

Our study was the first one to compare the differences in meditative effect of the three adiposity indices (BMI $\mathrm{z}$-score, WC, and PBF). Among them, BMI $\mathrm{z}$-score was the strongest one. Consistently, in our previous study, we also found that BMI had a stronger association with hypertension than WC, or PBF in normal-weight children [17]. This suggests that different role of these obesity indices in pathogenesis of childhood obesity. Further studies are warranted to replicate our findings.

Table 5 Adjusted meditative effect of z-score of three children's adiposity indices for the association between maternal overweight and history of hypertension, and z-score of children's blood pressure in 3316 Chinese school students

\begin{tabular}{|c|c|c|c|c|c|}
\hline \multirow[t]{2}{*}{ Mediator } & \multirow[t]{2}{*}{ Effect } & \multicolumn{2}{|l|}{ Overweight } & \multicolumn{2}{|c|}{ History of hypertension } \\
\hline & & SBP z-score & DBP z-score & SBP z-score & DBP z-score \\
\hline & Total effect & $0.2(0.08,0.32)$ & $0.19(0.09,0.3)$ & $0.3(0.06,0.54)$ & $0.31(0.11,0.5)$ \\
\hline \multirow[t]{3}{*}{ BMI z-score } & Indirect & $0.19(0.14,0.23)$ & $0.11(0.08,0.14)$ & $0.16(0.08,0.23)$ & $0.11(0.06,0.17)$ \\
\hline & Direct & $0.02(-0.13,0.16)$ & $0.09(-0.03,0.2)$ & $0.14(-0.11,0.4)$ & $0.19(-0.02,0.4)$ \\
\hline & Proportion & $92.2 \%$ & $55.6 \%$ & $52.0 \%$ & $37.3 \%$ \\
\hline \multirow[t]{3}{*}{ WC z-score } & Indirect & $0.1(0.07,0.14)$ & $0.06(0.04,0.08)$ & $0.15(0.08,0.21)$ & $0.08(0.04,0.12)$ \\
\hline & Direct & $0.1(-0.02,0.22)$ & $0.14(0.03,0.24)$ & $0.15(-0.08,0.38)$ & $0.22(0.03,0.42)$ \\
\hline & Proportion & $50.7 \%$ & $29.6 \%$ & $49.3 \%$ & $27.5 \%$ \\
\hline \multirow[t]{3}{*}{ PBF z-score } & Indirect & $0.11(0.07,0.14)$ & $0.07(0.04,0.09)$ & $0.17(0.1,0.24)$ & $0.11(0.06,0.16)$ \\
\hline & Direct & $0.09(-0.0 .03,0.21)$ & $0.13(0.02,0.23)$ & $0.13(-0.1,0.36)$ & $0.2(0.002,0.39)$ \\
\hline & Proportion & $53.8 \%$ & $35.7 \%$ & $56.9 \%$ & $36.0 \%$ \\
\hline
\end{tabular}

Paternal overweight includes overweight and obese $\left(B M I \geq 24.0 \mathrm{~kg} / \mathrm{m}^{2}\right)$. SBP systolic blood pressure, DBP diastolic blood pressure. $B M I$ body mass index, WC waist circumference, $P B F$ percentage of body fat

Adjusted for age $(\mathrm{y})$ and sex, height $(\mathrm{cm})$, birth weight $(\mathrm{g})$, infant feeding (breastfeeding, part breastfeeding or bottle-feeding), physical activities $(<1 \mathrm{~h}$ or $\geq 1 \mathrm{~h}$ per day), night sleep duration ( $<9 \mathrm{~h}$ or $\geq 9 \mathrm{~h}$ per day), consumption of carbonated beverage ( $\leq 3$ or $\geq 4$ bottles per week), western fast food ( $\leq 4$ or $\geq 5$ times per month), traditional Chinese fried food ( $\leq 4$ or $\geq 5$ times per week), and processed meat ( $\leq 4$ or $\geq 5$ times per week)

Proportion of meditative effect $=$ indirect effect/total effect ${ }^{*} 100 \%$ 
Our study had some limitations. First, we did not collect information on salt intake, one of major dietary determinants of hypertension risk. However, estimating salt intake using dietary records or food frequency questionnaire could be inaccurate. It is also not feasible to assess $24 \mathrm{~h}$ urinary sodium excretion as a biomarker of salt intake in a large population-based study [32]. Second, children's information on consumption of carbonated beverages, western fast food, traditional fried Chinese food, and processed meat as well as daily physical activities and night sleep assessed by a parental questionnaire which was subject to many biases (e.g., recall bias). Residual confounding should be taken into consideration. Residual confounding is also of concern. For example, parents' dietary behavior was not collected, which could have impact on both exposure and outcome in the current study [27]. We did not collect data on sexual maturation. Body size changed rapidly during puberty [33]. However, these data were transferred these into z-score, which might alleviate potential distractions. Finally, both paternal and maternal body weight was self-reported, which might result in misclassification. However, self-reported weight is generally accurate and had high correlation with measured weight [34]. The age and duration of hypertension for parents were not available in the current study. Further studies with deliberate information on parents are needed to warrant the results.

\section{Conclusions}

The association between parental information and children's blood pressure was mainly mediated by children's adiposity indices. Thus, paying more attentions to children's adiposity indices is meaningful to alleviate the effects of parental risk factor on their children health. Longitudinal studies with detailed information on dietary information in different ethnicity are warranted to confirm our findings.

\section{Additional file}

Additional file 1: Figure S1. The process of sample recruitment. Table S1. Partial correlation between parental BMl, and z-score of children's $\mathrm{BMI}$, waist circumference, percentage of body fat, and blood pressure in 3361 Chinese school students. Table S2. Mean difference and standard deviation of blood pressure $(\mathrm{mmHg})$ across parental groups in 3316 Chinese school students. Table S3. Adjusted meditative effect of z-score of three children's adiposity indices for the association between parental overweight and z-score of children's blood pressure in 3,316 Chinese school students. Table S4. Adjusted meditative effect of $z$-score of three children's adiposity indices for the association between parental history of hypertension and z-score of children's blood pressure in 3,316 Chinese school students (DOCX $229 \mathrm{~kb}$ )

\section{Abbreviations}

BMI: Body mass index; BP: Blood pressure; DBP: Diastolic blood pressure; PBF: Percentage of body fat; SBP: Systolic blood pressure; WC: Waist circumference

\section{Acknowledgements}

We appreciate some statistical work done by Dr. Hai-yan Yu.

Funding

The study was supported by the grants from Pu Dong Medical Bureau (PW2016D-05), and by the grant from Shanghai Key Laboratory of Pediatric Gastroenterology and Nutrition (No.17DZ2272000).

\section{Availability of data and materials}

All the datasets and SAS code are available upon readers' request.

\section{Authors' contributions}

RX designed the study, analyzed the data and drafted the paper; XZ and YZ collected the data and completed part of the data analysis; YW and XG approved the final paper. All authors read and approved the final manuscript.

\section{Ethics approval and consent to participate}

The study was approved by the Ethics Committee of Ren Ji Hospital, School of Medicine, Shanghai Jiao Tong University and parents signed informed consent forms.

\section{Consent for publication}

All authors have read and approved the submission of the manuscript. The manuscript has not been published and is not being considered for publication elsewhere, in whole or in part, in any language.

\section{Competing interests}

The authors declare that they have no competing interests.

\section{Publisher's Note}

Springer Nature remains neutral with regard to jurisdictional claims in published maps and institutional affiliations.

Received: 15 January 2019 Accepted: 1 May 2019

Published online: 27 May 2019

\section{References}

1. Yan W, Li X, Zhang Y, Niu D, Mu K, Ye Y, et al. Reevaluate secular trends of body size measurements and prevalence of hypertension among Chinese children and adolescents in past two decades. J Hypertens. 2016;34(12): 2337-43.

2. Khera R, Lu Y, Lu J, Saxena A, Nasir K, Jiang L, et al. Impact of 2017 ACC/ AHA guidelines on prevalence of hypertension and eligibility for antihypertensive treatment in United States and China: nationally representative cross sectional study. BMJ. 2018;362:k2357.

3. Pedrinelli R, Ballo P, Fiorentini C, Denti S, Galderisi M, Ganau A, et al. Hypertension and acute myocardial infarction: an overview. J Cardiovasc Med. 2012;13(3):194-202.

4. Nordahl H, Osler M, Frederiksen BL, Andersen I, Prescott E, Overvad K, et al. Combined effects of socioeconomic position, smoking, and hypertension on risk of ischemic and hemorrhagic stroke. Stroke. 2014;45(9):2582-7.

5. Lawlor DA, Najman JM, Sterne J, Williams GM, Ebrahim S, Davey Smith G. Associations of parental, birth, and early life characteristics with systolic blood pressure at 5 years of age: findings from the Mater-University study of pregnancy and its outcomes. Circulation. 2004;110(16):2417-23.

6. Ejtahed HS, Heshmat R, Motlagh ME, Hasani-Ranjbar S, Ziaodini H, Taheri M, et al. Association of parental obesity with cardiometabolic risk factors in their children: the CASPIAN-V study. PLoS One. 2018;13(4):e0193978.

7. Veena SR, Krishnaveni GV, Karat SC, Osmond C, Fall CH. Testing the fetal overnutrition hypothesis; the relationship of maternal and paternal adiposity to adiposity, insulin resistance and cardiovascular risk factors in Indian children. Public Health Nutr. 2013;16(9):1656-66.

8. Zinner SH, Levy PS, Kass EH. Familial aggregation of blood pressure in childhood. N Engl J Med. 1971;284(8):401-4.

9. Shi Y, de Groh M, Morrison H. Increasing blood pressure and its associated factors in Canadian children and adolescents from the Canadian health measures survey. BMC Public Health. 2012;12:388.

10. Dekkers JC, Treiber FA, Kapuku G, Snieder H. Differential influence of family history of hypertension and premature myocardial infarction on systolic 
blood pressure and left ventricular mass trajectories in youth. Pediatrics. 2003;111(6 Pt 1):1387-93.

11. Bouthoorn SH, Van Lenthe FJ, De Jonge LL, Hofman A, Van Osch-Gevers L, Jaddoe WW, et al. Maternal educational level and blood pressure, aortic stiffness, cardiovascular structure and functioning in childhood: the generation R study. Am J Hypertens. 2014;27(1):89-98.

12. Kwok MK, Schooling CM, Subramanian SV, Leung GM, Kawachi I. Pathways from parental educational attainment to adolescent blood pressure. J Hypertens. 2016;34(9):1787-95.

13. Xu HQHX, Liu AL, Zhang Q, Du SM, Lin R, Li TY, Guo HW, Ma GS. Prevalence of high blood pressure among children aged 6-13 years from six cities of China. Chin J Sch Health. 2012;32(12):1409-11.

14. Ip P, Ho FK, So HK, Chan DF, Ho M, Tso W, et al. Socioeconomic gradient in childhood obesity and hypertension: a multilevel population-based study in a Chinese community. PLoS One. 2016;11(6):e0156945.

15. Kaczmarek M, Stawinska-Witoszynska B, Krzyzaniak A, KrzywinskaWiewiorowska M, Siwinska A. Who is at higher risk of hypertension? Socioeconomic status differences in blood pressure among polish adolescents: a population-based ADOPOLNOR study. Eur J Pediatr. 2015; 174(11):1461-73

16. Lee CY, Lin WT, Tsai S, Hung YC, Wu PW, Yang YC, et al. Association of Parental Overweight and Cardiometabolic Diseases and pediatric adiposity and lifestyle factors with cardiovascular risk factor clustering in adolescents. Nutrients. 2016;8(9):E567. https://doi.org/10.3390/nu8090567.

17. Xu RY, Zhou YQ, Zhang XM, Wan YP, Gao X. Body mass index, waist circumference, body fat mass, and risk of developing hypertension in normal-weight children and adolescents. Nutr Metab Cardiovasc Dis. 2018; 28(10):1061-6.

18. Zhou B. Coorperative Meta-Analysis group of working group on obesity in C. [prospective study for cut-off points of body mass index in Chinese adults]. Zhonghua Liu Xing Bing Xue Za Zhi. 2002;23(6):431-4.

19. Update on the 1987 Task Force Report on High Blood Pressure in Children and Adolescents: a working group report from the National High Blood Pressure Education Program. National High Blood Pressure Education Program Working Group on Hypertension Control in Children and Adolescents. Pediatrics. 1996;98(4 Pt 1):649-58.

20. Dong Y, Ma J, Song Y, Dong B, Wang Z, Yang Z, et al. National Blood Pressure Reference for Chinese Han children and adolescents aged 7 to 17 years. Hypertension. 2017;70(5):897-906

21. Jiang YF, Cole T, Pan HQ, Lin ZF, Ju MF, Zhang L. Construction of height and weight percentile references for Shanghai children and adolescents. Shanghai J Prev Med. 2007;19(11):544-8.

22. Ji CY, Yt Sung R, Ma GS, Ma J, He ZH, Chen TJ. Waist circumference distribution of Chinese school-age children and adolescents. Biomed Environ Sci. 2010;23(1):12-20.

23. Sung RY, So HK, Choi KC, Li AM, Yin J, Nelson EA. Body fat measured by bioelectrical impedance in Hong Kong Chinese children. Hong Kong Med J. 2009;15(2):110-7.

24. Baron RM, Kenny DA. The moderator-mediator variable distinction in socia psychological research: conceptual, strategic, and statistical considerations. J Pers Soc Psychol. 1986;51(6):1173-82.

25. Preacher KJ, Hayes AF. SPSS and SAS procedures for estimating indirect effects in simple mediation models. Behav Res Methods Instrum Comput. 2004:36(4):717-31.

26. Wells JC. Commentary: paternal and maternal influences on offspring phenotype: the same, only different. Int J Epidemiol. 2014;43(3):772-4.

27. Wang Y, Beydoun MA, Li J, Liu Y, Moreno LA. Do children and their parents eat a similar diet? Resemblance in child and parental dietary intake: systematic review and meta-analysis. J Epidemiol Community Health. 2011; 65(2):177-89.

28. Smith BJ, Grunseit A, Hardy LL, King L, Wolfenden L, Milat A. Parental influences on child physical activity and screen viewing time: a population based study. BMC Public Health. 2010;10:593.

29. Abbasi J. The paternal epigenome makes its mark. JAMA. 2017;317(20): 2049-51.

30. Gupta-Malhotra M, Hashmi SS, Barratt MS, Milewicz DM, Shete S. Familia aggregation of first degree relatives of children with essential hypertension. Blood Press. 2018;27(5):289-96.

31. Stabouli S, Papakatsika S, Kotsis V. The role of obesity, salt and exercise on blood pressure in children and adolescents. Expert Rev Cardiovasc Ther. 2011;9(6):753-61.
32. Shi L, Krupp D, Remer T. Salt, fruit and vegetable consumption and blood pressure development: a longitudinal investigation in healthy children. $\mathrm{Br}$ J Nutr. 2014;111(4):662-71.

33. Adegboye AR, Andersen LB, Wedderkopp N, Heitmann BL. Influence of parental overweight on the association of birth weight and fat distribution later in childhood. Obes Facts. 2012;5(5):784-94.

34. Leary S, Davey Smith G, Ness A. No evidence of large differences in motherdaughter and father-son body mass index concordance in a large UK birth cohort. Int J Obes. 2010:34(7):1191-2.

\section{Ready to submit your research? Choose BMC and benefit from:}

- fast, convenient online submission

- thorough peer review by experienced researchers in your field

- rapid publication on acceptance

- support for research data, including large and complex data types

- gold Open Access which fosters wider collaboration and increased citations

- maximum visibility for your research: over $100 \mathrm{M}$ website views per year

At BMC, research is always in progress.

Learn more biomedcentral.com/submissions 